\title{
Directed Evolution of Artificial Imine Reductase
}

\author{
Martina Hestericováa ${ }^{[a]}$, Tillman Heinisch ${ }^{[a]}$, Lur Alonso-Cotchico ${ }^{[b]}$, J.-D. Maréchal ${ }^{*[b]}$, Pietro Vidossich ${ }^{[b]}$, \\ and Thomas R. Ward ${ }^{*}[a]$
}

\begin{abstract}
Artificial metalloenzymes, resulting from incorporation of a metal cofactor within a host protein, have received increasing attention in the last decade. Herein, we report on the directed evolution of an Artificial Transfer Hydrogenase (ATHase) based on the biotin-streptavidin technology using a straightforward optimized protocol allowing screening in cell free extracts. Our efforts yielded two streptavidin isoforms with improved catalytic activity and selectivity for the reduction of cyclic imines. Gratifyingly, the evolved ATHases proved stable under biphasic catalytic conditions. The X-ray structure analysis reveals that introducing bulky residues within the active site results in flexibility changes of the cofactor, thus increasing exposure of the metal to the protein surface and leading to a reversal of enantioselectivity. This hypothesis was confirmed by a multiscale approach based mostly on molecular dynamics and protein-ligand dockings.
\end{abstract}

Biocatalysis offers an attractive means to produce highadded value products. ${ }^{[1]}$ Its limitations in reaction repertoire, substrate scope and operational stability can be overcome using directed evolution or encapsulation techniques. ${ }^{[2]}$

Chiral amines, representing important intermediates for synthesis of biologically active compounds, agrochemicals, flavors and fragrances, are gaining increasing importance in both academic and industrial sectors. Since approximately $40 \%$ of all pharmaceuticals contain at least one chiral amine building block, ${ }^{[3]}$ the demand for their selective synthesis is immense. Current strategies to produce enantioenriched amines include organic synthesis, ${ }^{[4]}$ resolution of racemates ${ }^{[5]}$ or biocatalysis. ${ }^{[6]}$ Amine dehydrogenases,${ }^{[7]}$ phenylalanine ammonia lyases,${ }^{[8]}$ transaminase ${ }^{[9]}$ or imine reductase ${ }^{[10]}$ have been reported for chiral amine synthesis; monoamine oxidases ${ }^{[11]}$ and lipase ${ }^{[12]}$ for biocatalytic kinetic resolution of amines. Implementation of imine reductases in preparative biocatalysis remains a challenge, mainly because of the instability of the substrates in water, limited substrate acceptance, non-competitive price and a limited number of available enzymes. ${ }^{[10]}$

In the past fifteen years, biocatalysis has been complemented with artificial metalloenzymes (ArMs). These combine attractive features of enzymatic catalysis with the vast

[a] M. Hestericová, Dr. T. Heinisch, Prof. Dr. T. R. Ward Department Chemistry University of Basel

Mattenstrasse 24a, BPR 1096, Basel, 4002 (Switzerland)

E-mail: Thomas.ward@unibas.ch

[b] Lur Alonso-Cotchico, Dr. Pietro Vidossich, Prof. Dr. Jean-Didier Maréchal

Departament de Química

Universitat Autònoma de Barcelona

Edifici C.n., 08193 Cerdonyola del Vallès, Barcelona (Spain)

Supporting information for this article can be found under doi: XXX

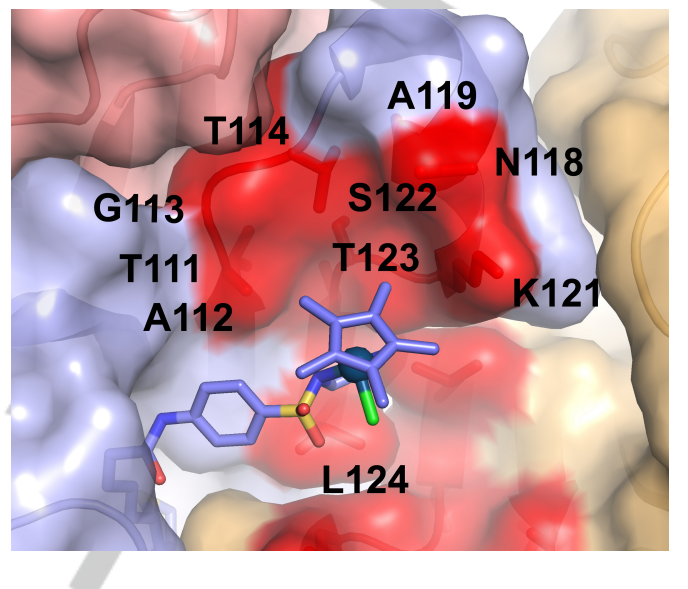

Figure 1. Close-up view of the active site of an artificial imine reductase. The protein is displayed as solvent accessible surface and the biotinylated cofactor as color-coded stick. Positions selected for mutagenesis are highlighted (PDB code: 3PK2).

reaction repertoire of organometallic catalysis. ${ }^{[13]}$ In this context, the biotin-streptavidin technology ${ }^{[14]}$ has proven versatile, allowing the development of numerous ArMs that have been optimized to catalyze new-to-nature transformations. ${ }^{[15]}$

In order to fine-tune the performance of enzymes, directed evolution has proven extremely powerful. ${ }^{[16]}$ Consisting of iterative cycles of (random) mutagenesis, protein overexpression and screening, this versatile technique allows to incrementally improve a targeted feature of an enzyme: activity, selectivity, stability etc. As ArMs consist of an abiotic cofactor and a genetically-encoded host protein, directed evolution can also be applied to the optimization of such hybrid catalysts. ${ }^{[17]}$

In order to speed-up the directed evolution of artificial metalloenzymes based on the biotin-streptavidin technology, we set out to perform catalysis using $E$. coli cell free extracts (cfe hereafter) rather than purified protein samples. Previously, we identified glutathione as a main contaminant, ${ }^{[18]}$ leading to the irreversible poisoning of the precious metal biotinylated cofactor when catalysis is performed in cfe. Addition of diamide (1,1azobis( $N, N$-dimethylformamide) to cfe containing streptavidin (Sav) prior to the addition of the cofactor restores to a large extent the catalytic performance of the ArMs. ${ }^{[18 b]}$ To test the usefulness of this straightforward screening protocol, we set out to optimize the performance of an artificial imine reductase based on the biotin-streptavidin technology by directed evolution.

In this work, we present the experimental implementation of a streamlined optimization protocol, ${ }^{[19]}$ which allows us to screen hundreds of mutant protein variants using cfe pre-incubated with diamide. Upon screening only 300 variants contained in cfe, which corresponds to approx. four weeks of mutagenesis and expression, four weeks of protein purification, and 200 hours of analytical measurements, two mutants with an increased catalytic 
activity and opposite selectivity for the reduction of cyclic imines were identified.

In order to improve the catalytic performance of the artificial imine reductase, we selected an area of $10 \AA$ around the iridium center of the biotinylated cofactor anchored within the streptavidin active site and subjected the corresponding amino acids to iterative saturation mutagenesis (Figure 1 and Supporting Information). As starting point for the screen, we used mature Sav ${ }^{[20]}$ with mutation K121A. For the first generation of the directed evolution, a reduced library of amino acids was included. At positions T111, S112, G113, T114, A116, N118, S122, T123 and $\mathrm{L} 124$, the following residues were introduced relying on precise primers: $A, V, L, D, E, Q, K, H, M, Y, S, P$ (or $N$ if one of the targeted mutation is present at this position). For the following generations, all canonical amino acids were individually introduced. Mutants were overexpressed in E. coli in 96 deep-well plates, and the cells were: i) lysed, ii) treated with diamide and incubated for 15 minutes, iii) supplemented with [C ${ }^{*} \mathrm{Ir}$ (biot- $p$ $\mathrm{L}) \mathrm{Cl}$ ] and iv) screened for the transfer hydrogenation of three cyclic imines 1a, 1b and 1c (Scheme 1, See SI for full experimental details). After identification of improved variants using cfe, the corresponding mutants were overexpressed in $1 \mathrm{~L}$ autoinduction ZYP- 5052 medium $^{[21]}$ in shake flasks, purified by iminobiotin-sepharose affinity chromatography and lyophilized. The pure Sav mutants were then tested for their ATHase activity in the presence of $\left[\mathrm{Cp}{ }^{*} \operatorname{Ir}(\right.$ biot $\left.-p-L) C l\right]$.

In the first generation, positions $\mathrm{S} 112$ and N118 were screened, yielding $(S)$ - and $(R)$-selective mutants $\mathrm{K} 121 \mathrm{~A}-\mathrm{S} 112 \mathrm{R}$ and K121A-N118P, respectively (Table 1, entries 4 and 5; Figure 2). Next, K121A-N118P was subjected to focused saturation mutagenesis in position S112. Mutant K121A-N118P-S112A yielded $(R)-2 a$ with an ee $=86 \%$ (entry 6 ). Position $\$ 122$ was mutated next. Substituting the polar serine to a methionine further improved the enantioselectivity for the reduction of $1 \mathrm{a}$, yielding $92 \%$ ee $(R)-2 a$ and full conversion (entry 7$)$. We hypothesized, that mutating alanine to bulky arginine at position 112 would afford the opposite enantiomer of $\mathbf{2 a}$. To our delight, the resulting Sav variant produced $(S)$-2a in $63 \%$ ee and with improved conversion (entry 9).

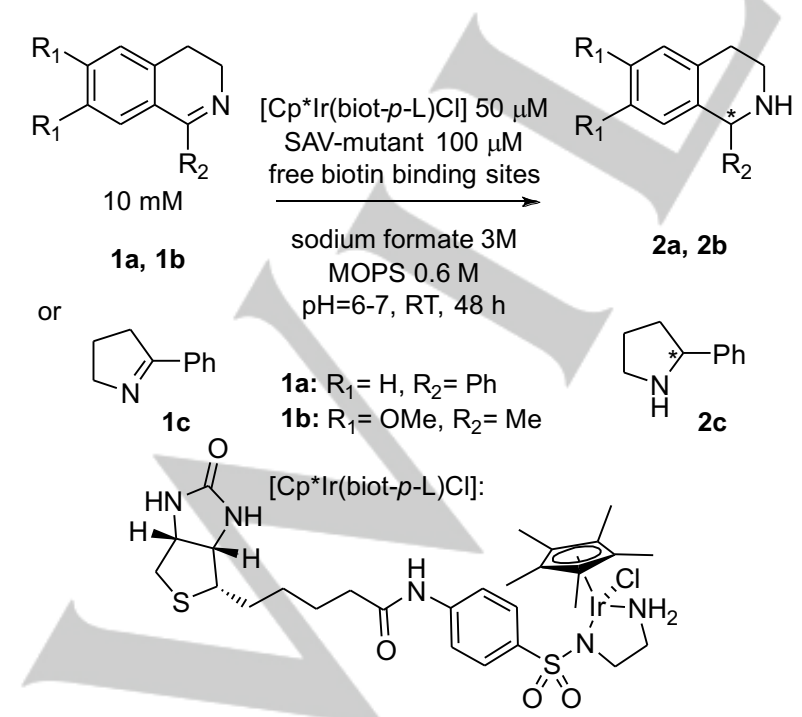

Scheme 1. Reduction of cyclic imines $\mathbf{1 a}, \mathbf{1 b}$ and $1 \mathrm{c}$ using ATHase based on the biotin-streptavidin technology.

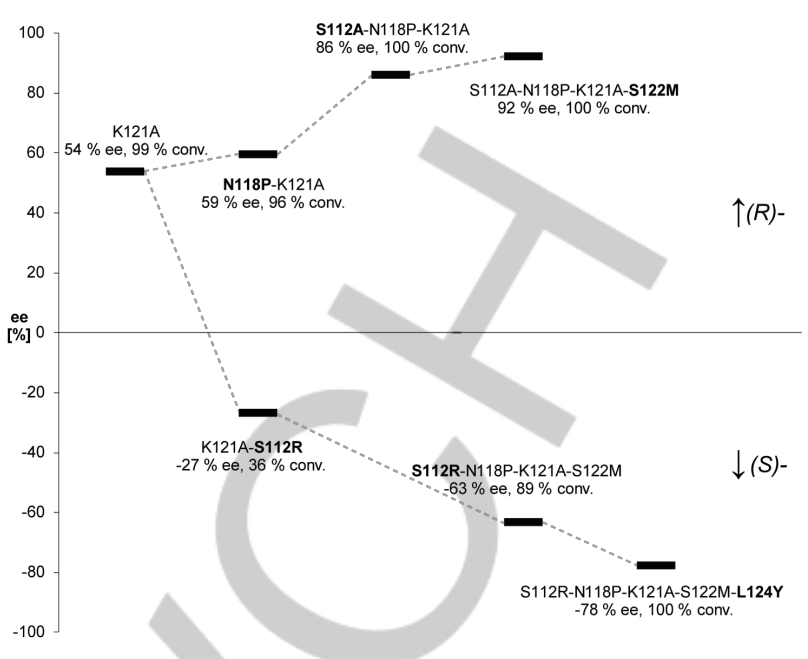

Figure 2. Summary of the directed evolution path to afford both an $(R)$ - and an (S)-selective ATHase for the reduction of $1 \mathrm{a}$.

The (S)-selectivity was further improved by introducing bulky tyrosine instead of lysine at position 124, which for the reduction of $1 \mathbf{a}$, yielded $(S)-2 a$ with an ee $=78 \%$ ee and full conversion (entry 10). Because of the low solubility of $\mathbf{1 a}$ in water, we performed experiments under a biphasic set-up ${ }^{[22]}$ with $100 \mathrm{mM}$ substrate 1a dissolved in ethyl acetate. To our delight, improved enantioselectivity was observed for both $(R)$ - and (S)-selective ATHases (entries 8 and 12). In stark contrast, [Cp*Ir(biot- $p-\mathrm{L}) \mathrm{Cl}]$ - K121A proved less active and less selective under biphasic conditions (entry 3). Preparative scale experiments (>120 mg of substrate) resulted in $>99 \%$ GC yield $(70 \%$ isolated yield) and $91 \%$ ee for Sav S112A-N118P-K121A-S122M and >75 \% GC yield ( $55 \%$ isolated yield) and $-71 \%$ ee for Sav S112R-N118PK121A-S122M-L124Y, respectively (Table 1, entries 9 and 13).

Table 1. Selected results for the reduction of cyclic imine 1a using purified proteins. ${ }^{[a]}$

\begin{tabular}{|c|c|c|c|c|}
\hline Entry & Sav source & $\begin{array}{c}\text { ee } \\
(\%)^{[d]}\end{array}$ & $\begin{array}{l}\text { conv. } \\
(\%)^{[d]}\end{array}$ & TON \\
\hline 1 & {$\left[\mathrm{Cp}{ }^{*} \operatorname{Ir}(\right.$ biot $\left.-p-\mathrm{L}) \mathrm{Cl}\right]$} & 0 & 17 & 35 \\
\hline 2 & $\mathrm{~K} 121 \mathrm{~A}$ & 54 & 99 & 198 \\
\hline 3 & $\mathrm{~K} 121 \mathrm{~A}^{[\mathrm{b}]}$ & 31 & 5 & 100 \\
\hline 4 & N118P-K121A & 59 & 96 & 193 \\
\hline 5 & S112R-K121A & -27 & 36 & 72 \\
\hline 6 & S112A-N118P-K121A & 86 & 100 & 200 \\
\hline 7 & S112A-N118P-K121A-S122M & 92 & 100 & 200 \\
\hline 8 & S112A-N118P-K121A-S122M[b] & 95 & 19 & 380 \\
\hline 9 & S112R-N118P-K121A-S122M[c] & 91 & $99\left(70^{\mathrm{e}}\right)$ & 198 \\
\hline 10 & S112R-N118P-K121A-S122M & -63 & 90 & 179 \\
\hline 11 & S112R-N118P-K121A-S122M-L124Y & -78 & 99 & 198 \\
\hline 12 & $\begin{array}{c}\text { S112R-N118P-K121A-S122M- } \\
\text { L124Y[b] }\end{array}$ & -85 & 11 & 220 \\
\hline 13 & $\begin{array}{c}\text { S112R-N118P-K121A-S122M- } \\
\text { L124Y[c] }\end{array}$ & -72 & $75\left(55^{\mathrm{e}}\right)$ & 150 \\
\hline
\end{tabular}

[a] The reactions were performed with $10 \mathrm{mM}$ substrate at $37^{\circ} \mathrm{C}$ for $48 \mathrm{~h}$ (see $\mathrm{SI}$ for details). ${ }^{[b]}$ Reactions were performed in a biphasic system with $100 \mathrm{mM}$ substrate at RT for 4 days. ${ }^{[c]}$ Preparative scale reaction, $124 \mathrm{mg}$ of 1a were added to $60 \mathrm{ml}$ of reaction mixture. ${ }^{[d]}$ Enantiomeric excess and conversion were determined by means of HPLC analysis. Positive ee values correspond to $(R)$ product and negative ee values correspond to (S)-product. ${ }^{\left[{ }^{[e]}\right.}$ Isolated yield. 
WILEY-VCH

COMMUNICATION

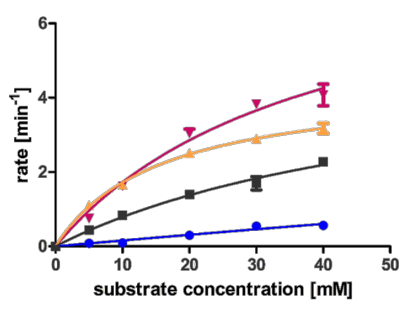

$1 b$

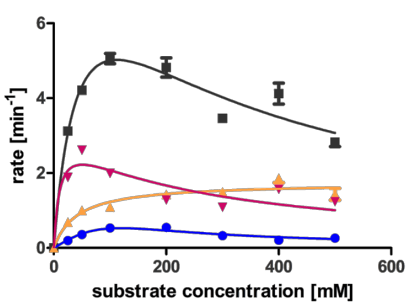

Scheme 2. - Saturation kinetic data for selected ATHases based on incorporation of $\left[\mathrm{Cp}^{*} \mathrm{Ir}(\right.$ biot- $\left.p-\mathrm{L}) \mathrm{Cl}\right]$ (2 eq.) in various Sav isoforms (1 eq.) for the reduction of imine $\mathbf{1} \mathbf{a}$ or $\mathbf{1 b}$. Error bars represent \pm standard deviation.

The resulting Sav library was tested for the reduction of the bulky isoquinoline $\mathbf{1 b}$ as well as cyclic imine 1c (Table S3). For the reduction of $\mathbf{1 b}$, an $(S)$-selective mutant following an evolution route bearing mutation $\mathrm{N} 118 \mathrm{~K}$ was identified: [Cp* $\operatorname{lr}($ biot- $p-\mathrm{L}) \mathrm{Cl}]$. S112T-N118K-K121A-S122K affords (S)-2b with an ee $=50 \%$ ee and $75 \%$ conversion after 48 hours (Table S3 entry 8, Figure S4). The highest (S)-selectivity for the reduction of 1c was obtained with Sav S112R-N118P-K121A-S122M-L124Y, yielding (S)-2c in an ee $=55 \%$ ee and $86 \%$ conversion (Table S3, entry 22, Figure S4).

Next, the saturation kinetic behavior of the bare cofactor as well as the best performing ATHases was determined (Scheme 2; Table S4). As can be appreciated from these data, mutant [Cp*Ir(biot- $p$-L)Cl] · Sav K121A displays an 8-fold increased $k_{\text {cat }}$ value for the reduction of $\mathbf{1 b}$ compared to the bare cofactor. Moreover, both mutants K121A-N118P-S112A-S122M and K121A-N118P-S112R-S122M-L124Y display improved reaction rates for the reduction of $\mathbf{1 b}$ compared to the bare cofactor. Introducing a bulky tyrosine residue at position 124 has a dramatic effect on $K_{\mathrm{M}}$, increasing its value to $50 \mathrm{mM}$ from $7.4 \mathrm{mM}$ for the bare cofactor. Both ATHase mutants S112R-N118P-K121AS122M-L124Y and S112A-N118P-K121A-S122M display very similar $K_{M}$ values, while their $k_{\text {cat }}$ differ significantly. This suggests that introducing a second bulky substituent at position 112 contributes to stabilization of the reaction transition state, thus improving the reaction rate for the (S)-selective ATHase. Substrate inhibition is encountered for mutants $\mathrm{K} 121 \mathrm{~A}$ and S112R-N118P-K121A-S122M-L124Y, whereas the free cofactor and mutant S112A-N118P-K121A-S122M display classical Michaelis-Menten kinetics, even at high substrate concentrations Unlike the results obtained from the reduction of $\mathbf{1 b}$, addressing the kinetic behavior of ATHases for the reduction of $1 \mathrm{a}$ revealed that none of the tested mutants could reach substrate inhibition dues to limited solubility of 1a. Compared to the bare cofactor, all mutants display slightly higher $k_{\text {cat }}$ coupled with lower $K_{M}$ values.

To gain structural insight into the best performing ATHases, crystals of S112R-N118P-K121A-S122M-L124Y and S112AN118P-K121A-S122M mutants were soaked with a solution containing an excess $\left[\mathrm{Cp}{ }^{*} \operatorname{Ir}(\right.$ biot- $p$ - $\left.\mathrm{L}) \mathrm{Cl}\right]$. Inspection of the $\mathrm{X}$-ray structure of [Cp*Ir(biot-p-L)Cl] · S112A-N118P-K121A-S122M Sav (Figure $3 a$ ) highlights the structural similarities to the structure of $\left[C p^{*} \operatorname{Ir}(\right.$ biot- $\left.p-L) C l\right] \cdot S 112 A$ Sav. ${ }^{[23]}$ The overall ATHase structure and the position and absolute configuration of

the piano stool moiety are virtually identical (RMSD of all $\mathrm{C} \alpha=$ 0.693). Due to potential steric clashes between two symmetryrelated cofactors, the chloride ligand was not modeled. However, the crystal structure suggests the preferred formation of an (S)configuration at the metal for $\left[\mathrm{Cp}^{*} \operatorname{Ir}(\right.$ biot- $\left.p-\mathrm{L}) \mathrm{Cl}\right]$ (i.e. $(R)$ configuration for the catalytically active hydride $\left[C p^{*} \operatorname{Ir}(\right.$ biot $\left.-p-L) H\right]$ ) (Figure S6A). The piano stool localization within the biotin-binding vestibule is stabilized by an $\mathrm{H}$-bond between the $\mathrm{A} 121$ backbone carbonyl oxygen and the amine nitrogen of the piano stool complex. As the cationic lysine residue at position K121 is substituted by an apolar alanine residue, it prevents a possible interaction with the imine nitrogen of the substrate. The nonconcerted transition state allowing $\mathrm{CH} \cdots \pi$ interaction between the $\mathrm{Cp}^{*}$ moiety and the phenyl of $1 \mathrm{a}$ allows for the formation of $(R)-$ 2a. The X-ray structure of $\left[\mathrm{Cp}{ }^{*} \operatorname{Ir}(\right.$ biot $\left.-p-\mathrm{L}) \mathrm{Cl}\right] \cdot \mathrm{S} 112 \mathrm{R}-\mathrm{N} 118 \mathrm{P}-$ K121A-S122M-L124Y Sav (Figure 3B) reveals that introducing bulky residues $S 112 \mathrm{R}$ and $\mathrm{L} 124 \mathrm{Y}$ within the Sav monomermonomer interface results in a nearly $180^{\circ}$ rotation of the piano stool moiety around the $\mathrm{C}_{\text {benzene-S }} \mathrm{S}_{\text {sulfonamide }}$ bond. The position of the pianostool is stabilized by an $\mathrm{H}$-bond between the $\mathrm{Y} 124$ side chain hydroxyl and the amino group of the cofactor (Figure S7B,C). Unfortunately, no electron density was present to model the $\left\{\mathrm{Cp}^{*} \mid \mathrm{rCl}\right\}$ moiety. We speculate that is may be due to increased flexibility of the surface-exposed complex or partial dissociation of the $\left\{\mathrm{Cp}^{*} \mathrm{IrCl}\right\}$. Increased cofactor exposure, presumably leads to increased solvent exposure of the substrate (Figure S7B). This is reminiscent to the structure of an ATHase $\left[\mathrm{Cp} p^{*}\right.$ Ir(biot- $\left.\left.p-\mathrm{L}\right) \mathrm{Cl}\right] \cdot \mathrm{S} 112 \mathrm{~K}$ Sav (PDB code 4OKA) ${ }^{[23]}$ Importantly, both crystal structures of the evolved ATHases presented herein reveal increased atomic B-factors within the loop-7,8 and the surface-exposed terminus of the cofactor when compared to published ATHases S112A and S112K (PDB 3PK2 and 4OKA respectively) (Figure S10, Table S5). ${ }^{[18]}$ In the latter structures, the loop-7,8 is conformationally rigidified by an $\mathrm{H}$-bonding network including i) the N118 side chain amide, ii) a water molecule and iii) the T115 backbone amide. Mutation N118P results in elimination of this $\mathrm{H}$-bonding network (Figure S11A). Additional flexibility is produced in loop 7,8 through mutation $\mathrm{S} 122 \mathrm{M}$ that induces breaking of $\mathrm{H}$-bonds in a Sav monomer-monomer interface (Figure S11B).

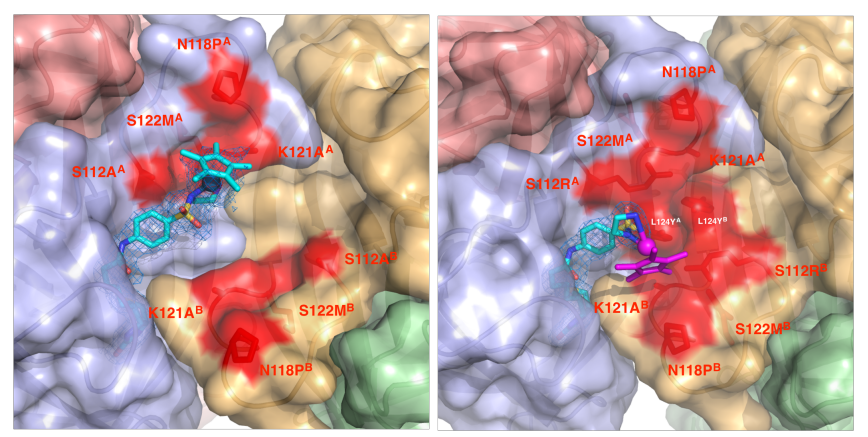

Figure 3. Close-up view of the crystal structures of complexes $\left[\left(\mathrm{Cp}^{*}\right) \operatorname{Ir}(\mathrm{Biot}-p\right.$ $\mathrm{L}) \mathrm{Cl}] \cdot \mathrm{S} 112 \mathrm{~A}-\mathrm{N} 118 \mathrm{P}-\mathrm{K} 121 \mathrm{~A}-\mathrm{S} 122 \mathrm{M}$ Sav (PDB 6ESS) $(\mathrm{A})$ and $\left[\left(\mathrm{Cp}^{*}\right) \operatorname{Ir}(\right.$ Biot- $p-$ $\mathrm{L}) \mathrm{Cl}$ - S112R-N118P-K121A-S122M -L124Y Sav (PDB 6ESU) (B). The protein is displayed as transparent surface and cartoon model with mutations highlighted in red in stick model. Only one cofactor per Sav tetramer is displayed for clarity. The cofactor is contoured with electron density from a 2FoFc map in marine $(1.0 \sigma)$ and an anomalous dispersion density map in red $(4.0 \sigma)$. Magenta atoms are not resolved in the electron density. 
These observations are reminiscent of the elevated atomic Bfactors found in the crystal structure of a Sav-based metathase. ${ }^{[17 f]}$

Crystal structures were determined assuming saturation of Sav monomers by the cofactor. However, catalysis was performed under a 1:2 ratio of cofactor per Sav monomer. To structurally characterize the assemblies under catalytic conditions, Molecular Dynamics (MD) simulations were performed using an implicit solvent approach and applying metadynamics to initially boost the exploration of conformational space (see Supporting Information for further details). The achiral planar catalytic [Ir(III)] $16 \mathrm{e}^{-}$two-legged pianostool was considered. Conformations from the MD trajectories were grouped (clustered) based on the cofactor position in the vestibule. The number of configurations in each group (cluster) is displayed in Figure S13a,b together with an estimate of the interaction energy between the [Ir] complex (excluding the biotin fragment) and the protein (Figure S13c,d). Variant S112R-N118P-K121A-S122M-L124Y was computed to bind the cofactor more tightly than variant S112A-N118P-K121A$\mathrm{S} 122 \mathrm{M}$. This observation may be explained based on the polarity of the residues in the vestibule, which is more hydrophobic for S112A-N118P-K121A-S122M. Accordingly, the MD trajectory of S112R-N118P-K121A-S122M-L124Y shows reduced mobility of the cofactor compared to S112A-N118P-K121A-S122M. The conformation of the cofactor in the most populated cluster in the trajectory of S112A-N118P-K121A-S122M is very similar to the $X$ ray determination (Figure S14A). However, further conformations are accessible to the cofactor via rotation around the $\mathrm{S}-\mathrm{N}$ bond (Figure S14B). Similarly, the conformation of the cofactor in the most populated cluster in the trajectory of S112R-N118P-K121A$\mathrm{S} 122 \mathrm{M}-\mathrm{L} 124 \mathrm{Y}$ is consistent with the $\mathrm{X}$-ray structure (See Figure $\mathrm{S} 12 \mathrm{C})$.

Next, we used this structural insight to rationalize the opposite enantioselectivity resulting from $\left[\mathrm{Cp}^{*} \operatorname{Ir}(\right.$ biot $\left.-p-\mathrm{L}) \mathrm{Cl}\right]$. S112R-N118P-K121A-S122M-L124Y and [Cp* Ir(biot- $p-L) C l]$ S112A-N118P-K121A-S122M variants towards substrate 1a. For this purpose, we docked the protonated form of $1 \mathrm{a}$ to the representative structures of selected clusters. The resulting structures were energy-minimized and the substrate binding energy estimated. We did not attempt to estimate reaction energies (i.e. with $\mathrm{QM} / \mathrm{MM}$ methods).

In the most populated cluster from the MD trajectory of S112R-N118P-K121A-S122M-L124Y Sav, [Cp*Ir(biot- $p-L) H]$ leads to the formation of $(R)-2 \mathrm{a}$. The best docking solutions for the pro- $R$ and pro- $S$ faces of 1a project the phenyl substituent in a pocket formed by residues $\mathrm{R} 112$ and $\mathrm{Y} 124$ from both monomers and P118 of the adjacent monomer. The difference between the two binding poses consists in the orientation of the imine plane: the $\mathrm{NH}$ group points towards the hydroxyl of tyrosine $\mathrm{Y} 124$ in the pro- $S$ structure (Figure $4 \mathrm{a}$ ), whereas it is rotated by 180 degrees and does not display interactions in the pro- $R$ structure (Figure $4 \mathrm{~b}$ ). From a docking point of view, the pro- $R$ binding mode is slightly favored over the pro-S one. However, MD simulations starting from these structures reveal that the pro- $R$ binding mode is not stable, whereas the pro-S displays a longer lifetime (i.e. about $200 \mathrm{ps}$ ). During this time, the $\mathrm{NH}$ group reorients to form an $\mathrm{H}$-bond to the backbone carbonyl of $\mathrm{A} 121$. Based on this data, we conclude that [Cp*Ir(biot- $p-L) H] \cdot S 112 R-N 118 P-K 121 A-S 122 M-$ L124Y Sav should preferentially reduce the pro-S face of $1 \mathrm{a}$, an observation in agreement with the experimental knowledge.

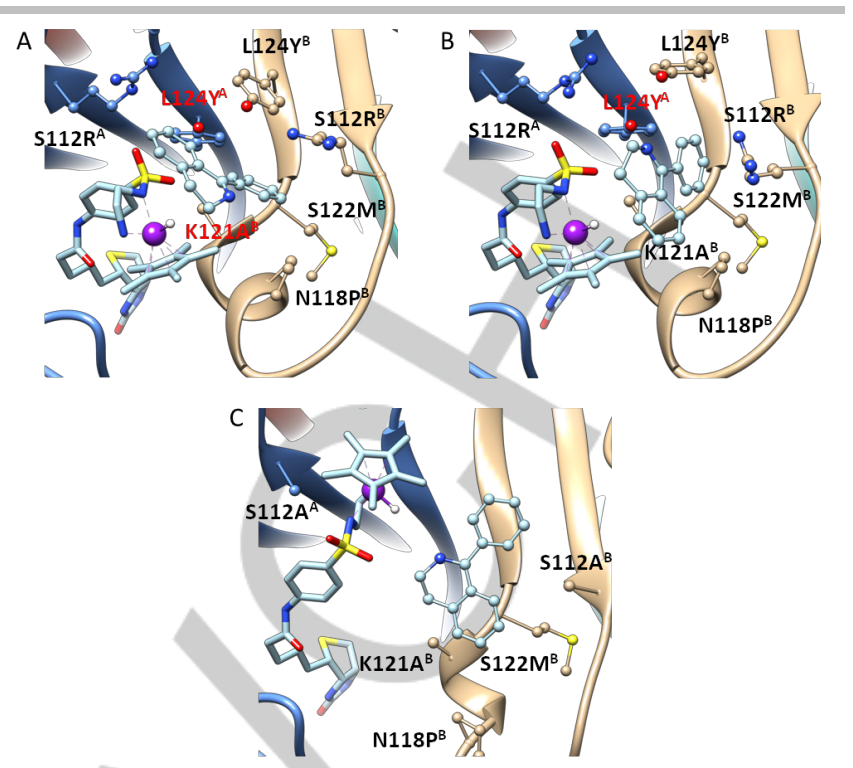

Figure 4. Substrate 1a docked to the most populated cluster from MD simulations of Sav variants S112R-N118P-K121A-S122M-L124Y (panel a and b) and S112A-N118P-K121A-S122M (c). The cofactor is shown in blue stick, with the $\mathrm{Cp}^{*}$ group in cyan and the $\mathrm{Ir}-\mathrm{H}$ atoms as balls; the substrate is shown as sticks with the reactive $C$ atom as a larger ball; the protein surface is shown in gray, with the residues within $4 \AA$ colored by type: white for hydrophobic residues, green for polar, blue for positively charged.

Concerning mutant S112A-N118P-K121A-S122M, docking of $1 \mathrm{a}$ to the representative structure of the most populated cluster (which would form the $(R)$-configuration of the metal-hydride) results in a binding mode with no clear preference for the reduction of either the pro- $R$ or the pro- $S$ faces of the substrate 1a. In this binding mode, 1a sits on the hydrophobic surface formed by residues L110, A112, T114, P118, A121, L124 (Figure 4c). We also considered binding of 1 a to representative structures of other clusters. In all cases, binding turned to be weaker than for the most populated. The MD simulations started from these bound structures did not reveal any alternative long-lived binding mode. It seems then that the ee observed experimentally for this mutant cannot be easily rationalized from a pure binding process and further aspects including the calculation of reaction barriers may be required.

In summary, introduction of a biotinylated iridium piano stool complex $\left[\mathrm{Cp}^{*} \operatorname{Ir}(\right.$ Biot$\left.-p-\mathrm{L}) \mathrm{Cl}\right]$ within streptavidin isoforms affords artificial imine reductases. These can be optimized by directed evolution protocols using cell free extracts (i.e. unpurified samples), thus dramatically improving the throughput of the effort. Two mutants with increased reaction rates and enantioselectivities were identified for the reduction of cyclic imine $\mathbf{1 a}$, allowing for the formation of both $(R)-\mathbf{2 a}(95 \%$ ee) and $(S)-\mathbf{2 a}$ ( $86 \%$ ee) using the same cofactor. The possibility of performing catalysis in a biphasic medium and on preparative scale paves the way for greater scope of applications of such hybrid catalysts. 


\section{Acknowledgements}

This research was supported by the Swiss Nanoscience Institute, and advanced ERC grant (DrEAM and the SNF (grant 200020 162348). TRW thanks Umicore for a generous loan of $\left[\mathrm{Cp}^{*} \mid \mathrm{rCl}_{2}\right]_{2}$. J-D.M., P. V. and L. A.C. are thankful for the support given by the Spanish grant CTQ2014-54071-P and the Generalitat de Catalunya grant 2014SGR989. Support of COST Action CM1306 is kindly acknowledged.

Keywords: artificial metalloenzymes • directed evolution • enzyme catalysis $\bullet$ transfer hydrogenation $\cdot$ cyclic imines

[1] a) U. T. Bornscheuer, G. W. Huisman, R. J. Kazlauskas, S. Lutz, J. C. Moore, K. Robins, Nature 2012, 485, 185-194., b) N. J. Turner, M. D. Truppo, Curr. Opin. Chem. Biol. 2013, 17, 212-214., c) M. T. Reetz, J Am. Chem. Soc. 2013, 135, 12480-12496., d) M. Hönig, P. Sondermann, N. J. Turner, E. M. Carreira, Angew. Chemie - Int. Ed. 2017, 56, 89428973.

[2] a) K. M. Polizzi, A. S. Bommarius, J. M. Broering, J. F. Chaparro-Riggers, Curr. Opin. Chem. Biol. 2007, 11, 220-225., b) N. R. Mohamad, N. H. C. Marzuki, N. A. Buang, F. Huyop, R. A. Wahab, Biotechnol. Biotechnol. Equip. 2015, 29, 205-220. c) M. Hestericová, M. R. Correro, M. Lenz, P. F.-X. Corvini, P. Shahgaldian, T. R. Ward, Chem. Commun. 2016, 52 , 9462-9465.

[3] Jarvis, L. M., Chem. Eng. News 2014, 94, 12-17.

[4] a) J. Renkel, Chiral Amin. Synth., Wiley-VCH Verlag GmbH \& Co. KGaA 2010, 1-49., b) T. C. Nugent, M. El-Shazly, Adv. Synth. Catal. 2010, 352 753-819.

[5] M. Breuer, K. Ditrich, T. Habicher, B. Hauer, M. Keßeler, R. Stürmer, T. Zelinski, Angew. Chemie - Int. Ed. 2004, 43, 788-824.

[6] a) G. Grogan, Curr. Opin. Chem. Biol. 2018, 43, 15-22., b) E. O'Reilly, N. J. Turner, Perspect. Sci. 2015, 4, 55-61., c) M. Nestl, S. C. Hammer, B. A. Nebel, B. Hauer, Angew. Chemie - Int. Ed. 2014, 53, 3070-3095 d) H. Kohls, F. Steffen-Munsberg, M. Höhne, Curr. Opin. Chem. Biol. 2014, 19, 180-192., e) D. Ghislieri, N. J. Turner, Top. Catal. 2014, 57, 284-300., f) F. Hollmann, I. W. C. E. Arends, D. Holtmann, Green Chem. 2011, 13, 2285., g) M. Hall, A. S. Bommarius, Chem. Rev. 2011, 111 4088-4110., h) M. Höhne, U. T. Bornscheuer, Chem CatChem 2009, 1 42-51.

[7] a) T. Knaus, W. Böhmer, F. G. Mutti, Green Chem. 2017, 19, 453-463. b) M. J. Abrahamson, E. Vázquez-Figueroa, N. B. Woodall, J. C. Moore A. S. Bommarius, Angew. Chemie - Int. Ed. 2012, 51, 3969-3972., c) F G. Mutti, T. Knaus, N. S. Scrutton, M. Breuer, N. J. Turner, Science 2015 , 349, 1525-1529.

[8] a) M. M. Heberling, B. Wu, S. Bartsch, D. B. Janssen, Curr. Opin. Chem. Biol. 2013, 17, 250-260., b) B. DeLange, D. J. Hyett, P. J. D. Maas, D. Mink, F. B. J. van Assema, N. Sereinig, A. H. M. de Vries, J. G. de Vries, ChemCatChem 2011, 3, 289-292., c) A. Gloge, J. Zon, A. Kovari, L. Poppe, J. Rétey, Chem-Eur J 2000, 6, 3386-3390.

[9] a) H. Brundiek, M. Höhne, Appl. Biocatal. From Fundam. Sci. to Ind. Appl. 2016, 199-218., b) R. C. Simon, N. Richter, E. Busto, W. Kroutil, ACS Catal. 2014, 4, 129-143., c) C. E. Paul, M. Rodríguez-Mata, E. Busto, I. Lavandera, V. Gotor-Fernández, V. Gotor, S. García-Cerrada, J. Mendiola, Ó. De Frutos, I. Collado, Org. Process Res. Dev. 2014, 18 788-792., d) S. Mathew, H. Yun, ACS Catal. 2012, 2, 993-1001., e) C K. Saville, J. M. Janey, W. R. Jarvis, J. C. Colbeck, A. Krebber, F. J. Fleitz, J. Brands, Science (80-. ). 2010, 329, 305-310.

[10] a) M. Lenz, N. Borlinghaus, L. Weinmann, B. M. Nestl, World J. Microbiol. Biotechnol. 2017, 33, 199., b) J. Mangas-Sanchez, S. P. France, S. L. Montgomery, G. A. Aleku, H. Man, M. Sharma, J. I. Ramsden, G Grogan, N. J. Turner, Curr. Opin. Chem. Biol. 2017, 37, 19-25.,c) Z. Maugeri, D. Rother, J. Biotechnol. 2017, 258, 167-170., d) Z. Maugeri, D. Rother, J. Biotechnol. 2017, 258, 167-170., e) M. Gand, H. Müller, R Wardenga, M. Höhne, J. Mol. Catal. B Enzym. 2014, 110, 126-132.

[11] a) S. Herter, F. Medina, S. Wagschal, C. Benhaïm, F. Leipold, N. J. Turner, Bioorganic Med. Chem. 2017, DOI 10.1016/j.bmc.2017.07.023., b) P. Zajkoska, M. Cárdenas-Fernández, G. J. Lye, M. Rosenberg, N. J. Turner, M. Rebroš, J. Chem. Technol. Biotechnol. 2017, 92, 1558-1565. c) N. Scalacci, G. W. Black, G. Mattedi, N. L. Brown, N. J. Turner, D. Castagnolo, ACS Catal. 2017, 7, 1295-1300., d) R. S. Heath, M. Pontini, S. Hussain, N. J. Turner, ChemCatChem 2016, 8, 117-120., e) D. Ghislieri, A. P. Green, M. Pontini, S. C. Willies, I. Rowles, A. Frank, G. Grogan, N. J. Turner, J. Am. Chem. Soc. 2013, 135, 10863-10869.

[12] a) Z. S. Seddigi, M. S. Malik, S. A. Ahmed, A. O. Babalghith, A. Kamal, Coord. Chem. Rev. 2017, 348, 54-70., b) F. Balkenhohl, K. Ditrich, B.
Hauer, W. Ladner, J. für Prakt. Chemie/Chemiker-Zeitung 1997, 339, 381-384., c) F. Balkenhohl, K. Ditrich, B. Hauer, W. Ladner, J. für Prakt. Chemie/Chemiker-Zeitung 1997, 339, 381-384., d) J. Paetzold, J. E. Bäckvall, J. Am. Chem. Soc. 2005, 127, 17620-17621.

[13] a) M. E. Wilson, G. M. Whitesides, J. Am. Chem. Soc. 1978, 100, 306307., b) C.-C. Lin, C.-W. Lin, A. C. S. Chan, Tetrahedron: Asymmetry 1999, 10, 1887-1893., c) F. Schwizer, Y. Okamoto, T. Heinisch, Y. Gu, M. M. Pellizzoni, V. Lebrun, R. Reuter, V. Köhler, J. C. Lewis, T. R. Ward, Chem. Rev. 2017, acs.chemrev.7b00014. d) J. Bos, F. Fusetti, A. J. M. Driessen, G. Roelfes, Angew. Chemie - Int. Ed. 2012, 51, 7472-7475., e) M. Pellizzoni, G. Facchetti, R. Gandolfi, M. Fusè, A. Contini, I. Rimoldi, ChemCatChem 2016, 8, 1665-1670., f) T. K. Hyster, L. Knörr, T. R. Ward, T. Rovis, Science 2012, 338, 500-503., g) J. Podtetenieff, A. Taglieber, E. Bill, E. J. Reijerse, M. T. Reetz, Angew. Chemie - Int. Ed. 2010, 49, 5151-5155., h) J. Bos, G. Roelfes, Curr. Opin. Chem. Biol. 2014, 19, $135-143$.

[14] a) M. T. Reetz, J. J.-P. Peyralans, A. Maichele, Y. Fu, M. Maywald, Chem. Commun. 2006, 4318., b) T. Heinisch, T. R. Ward, Acc. Chem. Res. 2016, 49, 1711-1721., c) C. Letondor, N. Humbert, T. R. Ward, Proc. Natl. Acad. Sci. 2005, 102, 4683-4687.

[15] a) H. Renata, Z. J. Wang, F. H. Arnold, Angew. Chemie - Int. Ed. 2015, 54, 3351-3367., b) T. K. Hyster, T. R. Ward, Angew. Chemie - Int. Ed. 2016, 2-16., c) M. Jeschek, S. Panke, T. R. Ward, Trends Biotechnol. 2017, j.tibtech.2017.10.003.

[16] a) M. T. Reetz, A. Zonta, K. Schimossek, K.-E. Jaeger, K. Liebeton, K.E. Jaeger, Angew. Chem. Int. Ed. Engl. 1997, 36, 2830-2832., b) M. T. Reetz, K.-E. Jaeger, Top. Curr. Chem. 1999, 200, 31., c) O. May, P. T. Nguyen, F. H. Arnold, Nat. Biotechnol. 2000, 18, 317-320., d) E. T. Farinas, T. Bulter, F. H. Arnold, Curr. Opin. Biotechnol. 2001, 12, 545551., e) M. S. Packer, D. R. Liu, Nat. Rev. Genet. 2015, 16, 379-394., f) C. A. Denard, H. Ren, H. Zhao, Curr. Opin. Chem. Biol. 2015, 25, 5564., f) M. T. Reetz, S. Wu, H. Zheng, S. Prasad, Pure Appl. Chem. 2010, 82, 1575-1584.

[17] a) M. T. Reetz, Tetrahedron 2002, 58, 6595-6602., b) E. M. Brustad, F H. Arnold, Curr. Opin. Chem. Biol. 2011, 15, 201-210., c) A. Ilie, M. T. Reetz, Isr. J. Chem. 2015, 55, 51-60., d), H. M. Key, P. Dydio, D. S. Clark, J. F. Hartwig, Nature 2016, 534, 534-537., e) P. Dydio, H. M. Key A. Nazarenko, J. Y.-E. Rha, V. Seyedkazemi, D. S. Clark, J. F. Hartwig, Science 2016, 354, 102-106., f), M. Jeschek, R. Reuter, T. Heinisch, C. Trindler, J. Klehr, S. Panke, T. R. Ward, Nature 2016, 537, 661-665.

[18] a) B. D. Bennett, E. H. Kimball, M. Gao, R. Osterhout, S. J. Van Dien, J. D. Rabinowitz, Nat. Chem. Biol. 2009, 5, 593-599., b) Y. M. Wilson, M. Dürrenberger, E. S. Nogueira, T. R. Ward, J. Am. Chem. Soc. 2014, 136, 8928-8932.

[19] H. Mallin, M. Hestericová, R. Reuter, T. R. Ward, Nat. Protoc. 2016, 11, 835-852.

[10] T. Sano, C. R. Cantor, Proc. Natl. Acad. Sci. 1990, 87, 142-146.

[21] F. W. Studier, Protein Expr. Purif. 2005, 41, 207-234.

[22] U. E. Rusbandi, C. Lo, M. Skander, A. Ivanova, M. Creus, N. Humbert, T. R. Ward, Adv. Synth. Catal. 2007, 349, 1923-1930.

[23] a) M. Dürrenberger, T. Heinisch, Y. M. Wilson, T. Rossel, E. Nogueira, L. Knörr, A. Mutschler, K. Kersten, M. J. Zimbron, J. Pierron, et al., Angew. Chemie - Int. Ed. 2011, 50, 3026-3029., b) V. M. Robles, M. Dürrenberger, T. Heinisch, A. Lledós, T. Schirmer, T. R. Ward, J.-D. Maréchal, J. Am. Chem. Soc. 2014, 136, 15676-15683. 
WILEY-VCH 